\title{
Traditional folk houses in Nantong under the background of Confucian Ethics
}

\author{
Xin Zhou \\ Soochow University, Suzhou, Jiangsu, 215000, China; \\ Yanshan University, Qinhuangdao, Hebei, 066000, China
}

Keawords: Confucian ethics, Nantong, folk house

\begin{abstract}
The Confucian style flourished in Nantong area, so the Confucian ethics involved in the construction of residential buildings. In these buildings, "heaven" and "people" blend with each other, reflected in everything from layout to decoration. This paper starts from the discussion of the spirit of Confucian ethics, then thinking of the embodiment of Confucian culture with regional characteristics in theresidential buildings.
\end{abstract}

\section{Introduction}

People often say, " The unique features of a local environment always give special characteristics to its inhabitants. ", in Nantong, it also formed a very unique regional cultural style, is both inclusive and independent. On one hand, it 's modest, mapping out the continuing impact of the ancient culture from the surrounding areas . And on the other hand, it is full of pioneering and independence spirit, which reflects a high degree of self awareness in every aspects. This cultural features envolves many factors, in addition to the climate, environment, geography and folk customs, the Confucian culture, especially its ethics is also a key factor. It can affects a lot of things, which has a profound impact on the local material civilization.

\section{The adoration for Confucianism in Nantong}

Although Nantong locates in the mouth of the Changjiang River, the ancestors of this land respect for the culture and the education, especially the Confucian culture . This phenomenon begans from the Song dynasty. According to historical records, since the beginning of 980 AD, Nantong establish the state school to educate the people of Confucianism. Since then the traditional Confucian culture took root here firmly. In addition to the state school, the academy, the primary schools, the community schools, the private schools have been born from here, which greatly enhance the quality of the local population. According to the statistics, during both of the Ming and Qing dynasties ,the Nantong city have the presented scholars up to 100 . If we take into account its limited size and population, which is great . In General, the prosperity of Confucian education not oniy has effectively promoted the quality of the local population, but also have laid the foundations for the development of the region .

The respect for the culture in Nantong has been inherited and further developed, but also was integrated into the ordinary people's lives, and which is inseparable from the promotion of Zhang Jian. Zhang Jian regarded himself a Confucian scholar all his life and worked hardly for the benefit of the people, improving the people's livelihood as his duty. All his life he respected the concept of servicing social, he founded numerous industrial projects, all kinds of schools, and optimizing the urban environment. It is worth noting that althoughZhang Jian 's means is new, the spirit of Confucian ethics in his philosophy is deeply rooted .The latter has been passed into the local people's lives and behaviors deeply through the education and social services.

\section{The Confucian ethics and the reality of life: the integration of the Heaven and the Humanity}

Confucian culture is a whole system, of course, it also contains many levels, so in the whole 
which is complex and diverse. This culture, which has lasted for more than 2000 years, always changed and adjusted its own form with the social and political environment. And at the same time, it has always been insisted its ethical value, Which have far-reaching impacts on China's political system and the secular life. And then it created a set of specification: they are not just in the way of people's behavior They don't just affect the people's behavior and also intervene in the face of material life deeply. and then maintains the social stability in China for thousands of years.Behind this kind of ethical spirit, in fact, Here lurks a dualistic structure of the interaction between the "heaven" and the "man".

If we traced back and will know, the interaction between the "heaven" and the "man" comes from the ancient religious beliefs actually . For the Confucian scholars, they believes that that Heaven have the potential and subtle effects on human beings, The former regulates the latter, and the human beings will be responsible for their words and deeds. Because God will make the corresponding punishment according to the words and deeds of good and evil, the day the supreme authority is undeniable. For alongside the people between heaven and earth, heaven only follow the principle, in order to obtain happiness and peace.

However, "heaven" is also not in the Confucian scholars really care about, In the final analysis, the fundamental problem they are concerned with is "humanity" ", What they cared about is that how people can live between the society and the earth. so this is actually about people's self positioning and self realization of the problem. Just as Du Weiming pointed out, "the basic concern of the Confucian tradition is how to learn to be an adult. The Confucian scholars emphasis that the Man who are not a beings which against the nature and the universe ,but seek harmony with nature and the heaven... In the Confucian view, learning to adult is a continuous expansion and deepening of the process. In this process. It is understood that all forms of human condition are in a state of mutual contact. Through such an expanding network of relationships which including the family, the society, the nation, the world, and God. , the Confucian seeks to achieve humanity in a comprehensive way." 1 , $\mathrm{n}$ this case, the "learning to adults" shows a kind of attitude, which means that, between the process of life, the people could realize the harmony between themselves and the nature by the continuous learning and edification.And they need always held the Feeling of awe and cautiousness from first to last. Only by this way,the people could become a gentleman gradually. It is necessary to point out that this process of living and learning seems need to be last all of a lifetime, which is t not once and for all.

So, how doe the ancestors acquire this kind of ethics consciousness? In fact, this is a subtle and repeated process. Through their own self-cultivation, the people could become sensitive and open-minded, and does not lack of the spirit of self reflection. And then, the environment surrounding with the people also needed to be created deliberately, in order to strengthen the ethical consciousness of people. So the resulting experience is delicate and subtle. In most cases, all of this revolve around the daily life and expand .In the visible and available buildings, utensils, clothes and all aspects, which are showing an ethical requirements. Obviously, their shape, decoration , color and material, which of these clearly don't give priority to aesthetics and pleasure, but intended to express a message, It requires people always remember the presence of the" heaven" and the fate.

This two-way, interactive structure based on reality, to meet the needs of people's reality.On the other hand, it also reflects people's values。 Through which, the people began to examine and understand the outside world , and then promoted their personality.The traditional architecture are providing such a node, a intermediary, so it is often seen as the most direct and most vivid carrier of Confucian ethics, which contains a rich and distinctive cultural connotation, " As an important cultural form, the construction is not a accumulation which is piled up by the dead matter, but condensed, ignited people's thoughts, feelings and beliefs about the meaning carrier... The building consists of the world of Human being's existence significance, and is also an important way, through which we can understand the world and participate in the world..".2。

\footnotetext{
"Confucianism" Du Weiming, Chen Jing translation, Shanghai ancient books publishing house February 2008 first edition, 3-4

${ }^{2}$ Chen Hui, "the four theory of Chinese classical architecture", Shanghai Fudan University press, the first edition in August 2012, the 47 page
} 
The traditional building is an excellent carrier of Confucian ethics. From the palaces , the private gardens to the ordinary houses, all of these reflect this point. Usually, the former show the authority which is too profound to be understood and the sense of a condescending oppression. However, the latter's character is clearly don't like the former, which has a kind of affinity, closing to the to ordinary people's life and their spiritual needs. Of course, the residential building also has its complexity, because it is a general concept, and serves for the different groups of people.From the merchants to the ordinary citizens, the traders and the handicraft makers, the needs of which are different. But totally they all have the similar ethical pursuit.

\section{The main embodiment of Confucian ethics in the residential buildings of Nantong}

In the residential buildings in Nantong area, the spirit of Confucian ethics is mainly reflected in the following aspects:

\section{The rites and music system}

Essentially the Confucian ethics inherited and developed from the rites of Zhou, Dynasty. For the Confucian ethics, the ritual system is seemed as the road to realize the social and political ideal.The Confucian scholars thought that it's necessary to establish a set of the basic etiquette, rites and music.in order to obtain the harmony order among the various classes. The concept of " rites and music " includes "ritual" and "music". In essence, the two is dialectical, blend。 The former is the purpose, and the latter is the means and carrier of the maintenance of the former.In when the context of Confucius, "music" contains mainly refers to poetry, music and dance.They are not usually in the form of entertainment, but a standard message to transfer sense of rank and order.

The layout of traditional China building emphasizes the plane layout, while the axial symmetry is one of the main features. Both of the Nantong residential buildings and buildings in other areas pay more attention to the central axis base, which launches in both of the vertical and horizontal lines.But from the overall perspective, the horizontal expansion is more restrained, this kind of symmetry, a two in the same structure and other areas, mainly in order to cause a sense of decency, but also provides a convenient life.

On this basis, there is a more complex structure, which make a division in both of the left room and right room.And on the other hand, striking a more progressive in the longitudinal space, through the repeated overlaps the courtyard units, thus forming " Two Enters ", "Three Enters" and so on. the nature of the space also become private from semi-private gradually.

\section{Moderation}

The Confucian ethics pay attention to "the Way of Moderation ", the so-called " Moderation ", is middle, neutralization, impartiality, non-excessive. That is to say, people should learn to grasp the limits of the development of things.

Nantong is located at the mouth of the sea, is by the sediment, so the history of its city is not too long. Therefore,its immigrants came from many areas, which carry diverse cultural nutrition.So its traditional houses in a large number of reference and absorbed from the architectural style of South of Jiangsu, Huizhou, Qilu and so on. Meanwhile,the' re good at the strain, so fully adapted to the local climate and natural environment. In Nantong,its courtyard buildings lie everywhere, like the rest of the other areas.But here are very small courtyard houses, the compound constitutes a narrow progressive relationship, and the relationship between the courtyards is more flexible and free.

For example, Nantong is quite symbolic of the two houses and the parallel layout. This kind of building is the brother of the two families and their neighbors, layout, orientation, structure is similar, but independent of each other, between the two has also opened a small door, to facilitate family communication and contact. Undoubtedly, the kinship as a link to the residential patterns can only from the aspect of social culture explained,which show that the ancient people of NanTong pay full attention to the ethical significance in the family house. This is a beautiful dream, and not lack of measured in careful moderation.

The road of harmony is also reflected in the residential construction of some obscure places, such as the corner of the wall. The corner of the external wall in these residence buildings is very 
characteristic. They are mostly like a chamfer or fillet which is avoid the potential danger, so they are been cut off from the top to the land. While the people walk in and out of the streets that they'e safety and convenience. So we can see, it not only fully protect the walls and buildings, but also reflect the humanistic thinking from the Confucian ethical spirit.

\section{Restraint}

And the thing which is closely related with Moderation is introverted ,both of which have a logical connection. And the latter also reflects the Confucian ethical spirit . Of course, understanding of the concept and expression, in different regions have different expression, also the Nantong architectural culture of which is a very important part. From the perspective of the overall style, Nantong residence is low-key, simple and plain.If we compare them with other areas in a horizontal comparison, you will find that this characteristic is so distinctive.In scale, them are not so tall as far as the houses in Huizhou, Jinzhong or South Jiangsu area .In the decorative effect, they are rarely as luxurious as the latter. In which the Brick and wood carving are used in a large number, in order to highlight the splendor and glory of the family.

As far as the style is concerned, the residential buildings in Nantong are low-key, restrained and non-publicity. They inhibited the building 's external image, and put more attention to the internal space.Taking the gate of these houses as an example, many messages are revealed in this structure. In many areas, people tend to be very concerned about the image and scale of the gate, because the gatehouse can indeed be regarded as a "face". But interestingly, the gate of the residential building in Nantong did not pursue the grand style. It seems that it is more low-key, rustic. Most of them are "Manzi" gate, of course, its production techniques is quite hard, majority is rubbed brickwork, also known as "dog bite". overall, the treatment of the door, whether its decoration, or its regulation, is to be weaker than the two door.

In the residential building, the cohesive force is reflected in the appearance of a low-key treatment, which separates the private life and the outer world,In many aspects of Nantong architecture reflects this point. Generally speaking, the main hall activities as the center of daily life. If it is directly toward the door, then from the feng shui point of view, this is not appropriate.So, for the rich and powerful people, the position between the main hall and the gate can set a screen. But for the well - off families, they need to find another way. In Nantong, more common approach is the so-called "key door", which located between the gate to the hall sets some transition area: General hall door, second gate, small courtyard, and so on.

\section{Conclusion}

Within the circle of Chinese culture, with a huge scale and complete system, the Confucian culture naturally has an immeasurable and overarching impact on the social life, then the residential buildings reflect this effect. And because the building is also affected by many other complicated factors, so they are always diverse and expressive, Confucian ethics always has a very diverse and specific forms.

In the residential buildings of Nantong, the ritual music system, moderation and Restraint are fully reflected. However, we will not confuse the residential buildings of Nantong with others, For example, the houses in Huizhou, Jinzhong, South of Jiangsu, Fujian which are also deeply influenced by Confucianism.In Nantong, Confucian ethical culture ,the fisheries and the merchant civilization are fused together naturally, which reflects the the complexity and the relativly stability in this cultural psychology. It is restrained, delicate, while also showing a relatively free and independent feature.

\section{Acknowledgments}

This paper was supported by the Fund Project: Jiangsu Province research students cultivate innovation project, "the 20th century western design criticism history research" (CXZZ12, heavy).

\section{Reference}


[1]. Wang Dongsheng Confucian ethics and Christian ethics comparative study of the second issue of the Journal of Chongqing Jiaotong University in 2009.

[2]. Six Wu Jingdong Confucian Ethics Discussion on the 2 concepts of modern philosophy in 2006 fifth.

[3]. Qin Hongling Confucian ethics and the Chinese traditional architecture of the new building in 2004 third.

[4]. of Confucianism Du Weiming, Chen Jing translation, Shanghai ancient books publishing house February 2008 first edition.

[5]. Chen Hui "China thought of four classical architecture theory". Shanghai: Fudan University press, August 2012 First Edition

[6]. Zhang Rongming "theory of yin and Zhou God" "Qilu journal" in 1992 fourth.

[7]. Tuan Sui Chang "benevolence and rite: moral autonomy and social constraints, see the Chinese universe view" edited by Huang Junjie, Hefei Huangshan bookstore, 2012 April first edition . 